\title{
Ecological state of the Upper Dnieper and its basin and prospects for the near future
}

\author{
G. Chernogaeva \\ Institute for Global Climate and Ecology under Roshydromet and the \\ Russian Academy of Science, Moscow, Russia
}

\begin{abstract}
The study was carried out in the framework of Project UNDP - GEF, devoted to ecological sanitation of the Dnieper-river using the GIWA procedure. The data of the long-term hydro chemical monitoring and hydro biological investigations, as well as the assessment by the GIWA procedure testify that at present, the Upper Dnieper water may be considered as moderately polluted. For the last decade the water quality has slightly improved due to the recession in industry and agriculture, but not adequately to the recession in production.

Biological diversity of the river decreased, mainly in connection with construction of a cascade of storage reservoirs in the middle stream of the Dnieper-river. The biological diversity in the Upper Dnieper basin has decreased for the last hundred years as a result of extensive land use and forestry.

Because of the Chernobyl accident consequences and the ecological crisis in our country, for the last decade the demographical situation in the Upper Dnieper basin has become worse: the birth-rate of the population has decreased, and the mortality has increased. Under the crisis conditions the share of GDP, spent for environmental activities, has sharply reduced.

The prospects of economic and ecological situation in the Upper Dnieper basin, based on the most favorable scenario of economic development, show that in the next 10-15 years the level of 1990 can be reached under conditions of the economic rise.

In situation provided by such a scenario, the pollution levels of the environment may exceed this of 2000 because of wear and tear of basic funds, including the treatment equipment.
\end{abstract}




\section{Environmental Health Risk}

\section{Introduction}

The Dnieper basin is a complicated river system with high economic, social and ecological value. This is a large economic diversified complex with high level of development and anthropogenic load on land water potential and biological diversity. Large settlements, many middle and small towns, industrial centres and agricultural lands are located on the area of the Dnieper basin.

The hydrographic network of the Dnieper basin is a green transboundary corridor for migration of birds of passage and other terrestrial and water organisms. The basin area includes different native zones and provinces; as a result, a great variety of population, species cenoses and geosystem composition was formed.

After the establishing in 1991 of independent countries of the Ukraine, Belarus and the Russian Federation, a sharp question arose on the mutual use and protection of these water resources (Fig. 1). Certain efforts have been made since 1992 to solve this problem within the framework of bilateral intergovernmental agreements between the CIS and EEC countries.

In 2002 in Kiev the Ukrainian-Russian Agreement was signed by the Ukrainian Cabinet of Ministers and the Government of the Russian Federation on mutual use and protection of transboundary water bodies. In the same year the Russian federation and the Ukraine signed Convention on Protection and Use of Transboundary Watercources and International Lakes (Helsinki). Since 1996 the Russian Federation, Belarus and the Ukraine (with the support of IDRC and PROON-GEF) have been carrying-out projects aimed to realisation of international programmes on ecological sanitation of the Dnieper basin.

After the disintegration of the USSR in 1992, the anthropogenic effect on the environment in the Upper Dnieper basin (Russian part) took place under the conditions of economic crisis. On the territory under consideration the loss of physical volumes in industry in 2000 was about two-third of these of the year of 1990. Investments decreased sharply, the rate of the decrease being higher than the recession in industry. For the last 20 years arable lands reduces by 168.3 thous. Ha. The life standards of the population dropped. All these have led to the decrease in anthropogenic load on the Upper Dnieper basin. However, the response of the environment and the changes in its quality were not adequate to the decrease in the load. First of all, it concerns the surface water quality [5].

\section{Surface water quality}

At present, less than 5 per cent of the total resources of surface sources are used in the Upper Dnieper basin. Almost the same volume is discharged. For the last 10 years intake of water from the surface sources decreased by nearly 30 per cent. First of all, it was stipulated by the intake of water for industrial needs. The intake for domestic and sanitary needs did not change in reality.

For the last 10 years discharge of pollutants with waste water (mainly by industrial enterprises) also reduces (Fig. 2). The discharge of pollutants with domestic and sanitary water remained at the same level. So, waste water of this 
Environmental Health Risk 27

\section{DNIEPER BASIN}

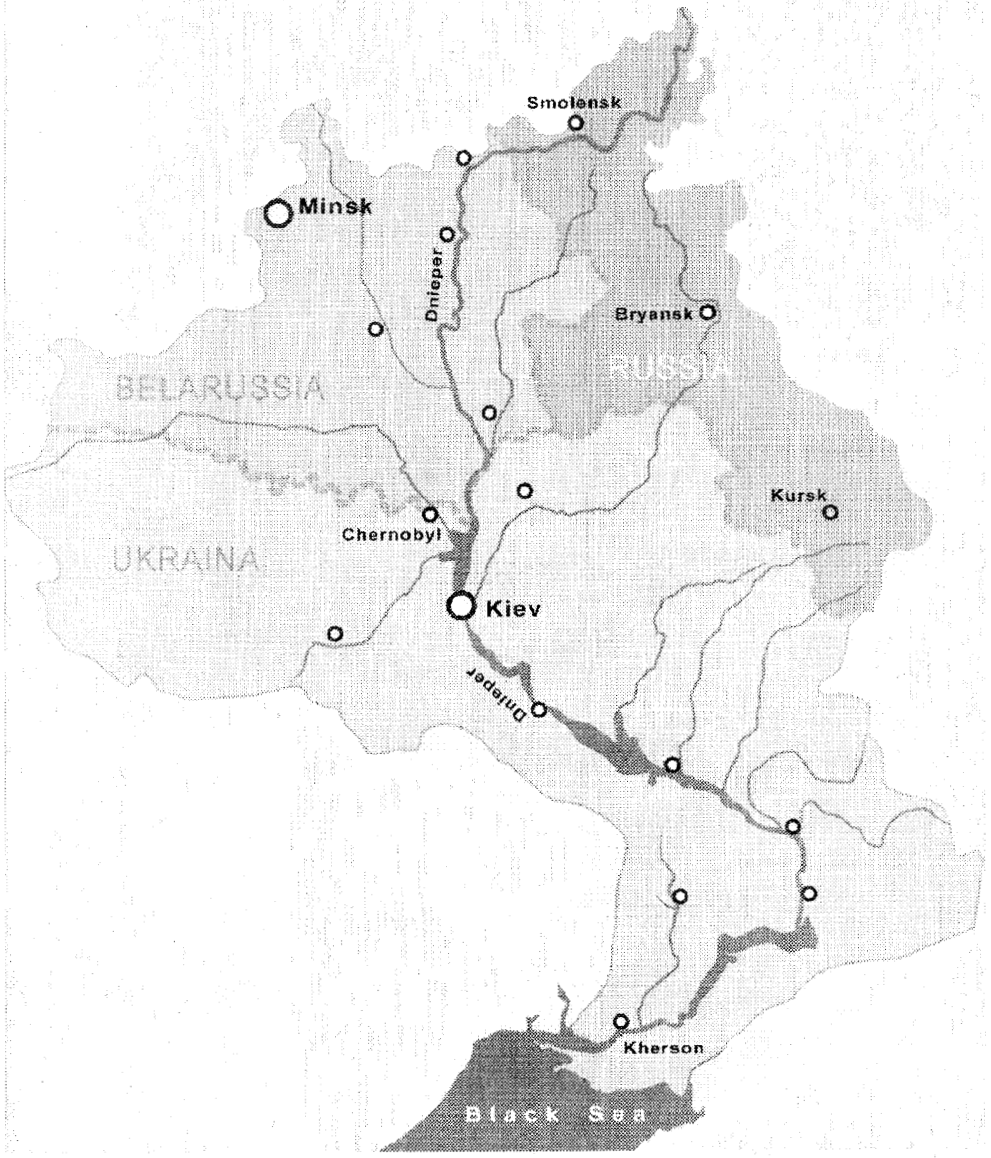

Figure 1: Dnieper Basin.

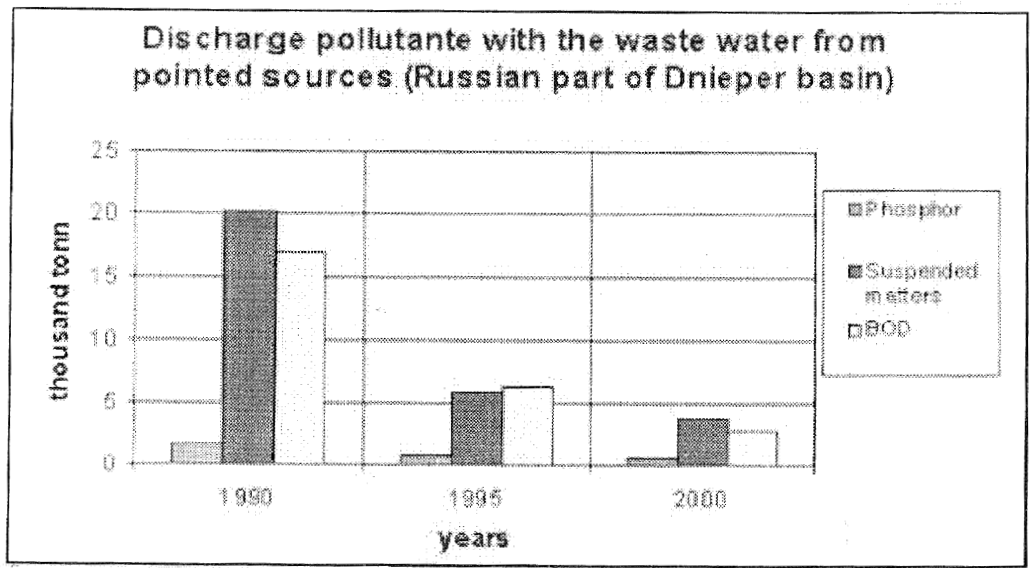

Figure 2: Tendency of discharge pollutante into the river. 


\section{Environmental Health Risk}

kind is now the priority source of surface water pollution in the Upper Dnieper basin. The main pollutants in domestic and sanitary water are biogenic and suspended matters. In practice, all domestic water is subject to the treatment. Only 6 per cent of its total volume is purified according to Russian standards. One should notice that the Russian standards for the quality of purified waste water are much higher than these in Europe. At present, they are revised toward more realistic ones.

Over 90 per cent of suspended and biogenic matter is taken out from the basin area by disseminated way with the sheet flow. For the last 10 years the sharp decrease in fertilization and live-stock population led to the reduction of nitrogen (3.5-fold) and phosphorus (nearly 20 per cent) taking-out from the catchment. The taking-out of suspended matter did not change considerably.

The data of long-term hydrochemical and hydrobiological monitoring of the surface water quality, the results of mutual (Russian-Belorussian-Ukrainian) field studies for the period of 2000-2001, as well as the estimation using the GIWA procedure, show the surface water quality in the Upper Dnieper basin may be characterised generally as "moderately polluted".

\section{Air pollution}

As to the atmospheric pollution in the region under consideration and the load of atmospheric deposition of pollutants on the ground surface, one can notice more pronounced changes as compared to the surface water pollution. Emissions from local sources reduces by 3-4 times for the last 10 years. In 2000 about 200 thous. $t$ of pollutants were totally emitted into the atmosphere in the region. The most considerable pollutants (on emission mass) were dust, sulphur dioxide, nitrogen oxides, carbon dioxide, lead [3].

According to the hydrometeorological service's observations, the air quality in the largest cities of the Upper Dnieper basin (Smolensk, Kursk, Bryansk) with the population number exceeding 300 thous. people in each one, is satisfactory. Mean annual values of pollutant concentrations on the priority indices do not exceed the existing standards.

The snow cover monitoring data and calculations of the load of atmospheric deposition of sulphates, nitrates and lead show that there are higher polluted areas around the mentioned cities, formed as a result of emissions from stationary pollution sources (Fig. 3). The whole load of atmospheric deposition on the ground surface of the catchment practically did not change for the last five years on the background regional level. The west transboundary transfer plays an essential role in the formation of the regional background of the atmospheric pollution. Up to 30 per cent of atmospheric deposition of pollutants on the territory of the Upper Dnieper basin are connected with the transfer from Belarus and the Ukraine (Fig. 3).

Acid precipitations do not occur practically because of the high concentrations of alkaline elements in emissions from local sources. So, no acidification of water bodies in the Russian part of Dnieper basin as a result of acid precipitation [1]. 


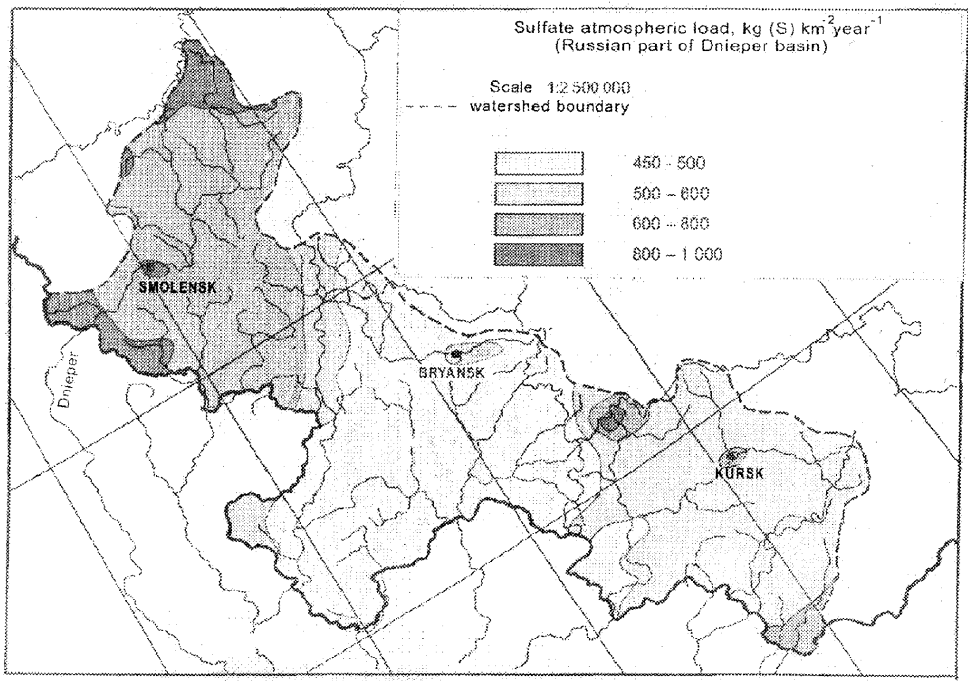

Figure 3: Sulfate atmospheric load.

\section{Soil}

The decrease in the pollutant emissions into the atmosphere, the drop in pesticide use and the reduction of arable lands leads to lower soil pollution. On the other hand, the drop in manuring, in fertilisation by mineral phosphorus, nitrogen and potassium is accompanied with continuous rise in the humus content and disintegration of the most valuable soil component - its absorbing complex. The degree of base saturation decreased by 30-40 per cent, $\mathrm{pH}$ shifted toward lower, acider one.

The caesium patterns with increased and high contamination levels, formed on the Russian territory of the Upper Dnieper basin as a result of the Chernobyl accident, coincide mainly with the forest zone with low-fertile podzolic and soddy podzolic soils.

By the year of 2046 (60 years after the ChNPP accident, two 137Cs decay periods) considerably contaminated areas (from the radioecological point of view) will reduce essentially. The Table shows that by the year of 2046 on the Russian territory of the Upper Dnieper basin the patterns with 137Cs contamination level above $30 \mathrm{Ku} / \mathrm{sq}$. $\mathrm{km}$ will disappear, and those with levels above $15 \mathrm{Ku} / \mathrm{sq} . \mathrm{km}$ will retain on limited catchment areas of minor tributaries of the Dnieper-river (Table, 1). The contamination levels will be nearly global on 56 cent of the Russian part of the Upper Dnieper basin [2]. 
Table 1. Areas with different levels of soil pollution (Russian part of the Upper Dnieper) ${ }^{137} \mathrm{Cs}$

\begin{tabular}{|c|c|c|c|c|c|c|c|c|c|c|c|c|c|c|}
\hline \multirow[t]{3}{*}{ Year } & \multicolumn{14}{|c|}{ Levels of pollution ${ }^{137} \mathrm{Cs}, \mathrm{Ku} / \mathrm{km}^{2}$} \\
\hline & \multicolumn{2}{|c|}{$>40$} & \multicolumn{2}{|c|}{15.40} & \multicolumn{2}{|c|}{$5-15$} & \multicolumn{2}{|c|}{$1-5$} & \multicolumn{2}{|c|}{$0,5-1$} & \multicolumn{2}{|c|}{$0,1-0,5$} & \multicolumn{2}{|c|}{$<0,1$} \\
\hline & $\begin{array}{c}\text { Th } \\
\mathrm{km}^{2}\end{array}$ & $\%$ & $\begin{array}{c}\mathrm{Th} \\
\mathrm{km}^{2}\end{array}$ & $\%$ & $\begin{array}{c}\mathrm{Th} \\
\mathrm{km} \\
2\end{array}$ & $\%$ & $\begin{array}{c}\mathrm{Th} \\
\mathrm{km} \\
2\end{array}$ & $\%$ & $\begin{array}{c}\mathrm{Th} \\
\mathrm{km} \\
2\end{array}$ & $\%$ & $\begin{array}{l}\text { Th } \\
\mathrm{km}^{2}\end{array}$ & $\%$ & $\begin{array}{c}\text { Th } \\
\mathrm{km}^{2}\end{array}$ & $\%$ \\
\hline 1986 & 0,58 & 0,1 & 2,07 & 0,5 & 3,1 & 0,7 & 74 & 19 & 71 & 17 & 252 & 62 & 3,0 & 0,7 \\
\hline 2002 & 0,05 & 0,01 & 1,5 & 0,3 & 2,7 & 0,7 & 41 & 10 & 53 & 13 & 293 & 72 & 15 & 4 \\
\hline 2046 & 0 & 0 & 0,1 & 0,02 & 1,5 & 0,4 & 27 & 6 & 10 & 2,6 & 143 & 35 & 224 & 56 \\
\hline
\end{tabular}

\section{Biota}

At present, the most part of the Upper Dnieper basin is covered by agrophytocenoses and pastures. Territories occupied by natural biogeocenoses are reduced southward from the forest zone to the steppe. Forests cover about 32 per cent of the total area of the basin, about 2 per cent are covered by bogged sites [4]. In the forest zone, the forest cover of small catchments may reach 80 per cent of their total areas. Southward, in the forest-steppe and steppe zones, the forest cover of individual catchments may fall up to 10 per cent and less. Within such catchments the forests are drawn towards hydrographic network. As was mentioned above, the hydrographic network of the Dnieper basin is a green passage for migration of birds and other terrestrial and water organisms. Investigations of the green passages, carried-out in the framework of the project under consideration, have indicated their satisfactory state on the territories of Belarus and Russia. So, migrating and roaming species predominate in ornithofauna of the Upper Dnieper basin (150 species), while there are not more than 20 settled ones.

\section{Conclusion}

In spite of the fact that the ecological state of the Upper Dnieper basin is estimated as satisfactory as a whole, the results of the conducted complex study point to a number of transboundary and local ecological problems.

The main transboundary problems of the Russian part of the Dnieper basin are the following:

- pass of high spring floods with providing of 25 per cent and less;

- atmospheric transboundary transfer of pollutants to the Russian territory;

- water transboundary transfer of pollutants from the Russian territory to Belarus and the Ukraine;

- preservation and reconstruction of the green passages for migration of birds. The transboundary problems will be solved in accordance with Strategic Action Programme being developed by three countries - Russia, Belarus and the Ukraine. This is the main goal of Programme PROON-GEF aimed at ecological sanitation of the Dnieper basin. 
The Program will identify the mechanism of sustainable protection of the third longest river in Europe, thus contributing to the protection of regional and global international water.

The local ecological problems of the Upper Dnieper basin will be solved in accordance with Concept of Sustainable Development of the Russian Federation, State Strategy of Use, Rehabilitation and Protection of Water Bodies on Russia, as well as the Federal Target Program "Russian Water - XXI". These documents are developed by the Ministry of Environmental Protection of the Russian Federation. They formulate requirements for the formation and improvement of economic activity (including the environmental protection measures) to ensure sustainable social and economic development and to preserve the environment.

\section{References}

[1] Chernogaeva, G., Acidification, A water quality assessment of the former Soviet Union. E and F Spon. London and New York. pp.293-311, 1998.

[2] Kvasnikova, E. and others, Modern radionuclide composition Chernobyl's falls for different distances from the place of accident. International Conference: Radiactivity of Nuclear Accidents. 24-25 April 2000, Moscow, volume 1, St. Petersburg, Hydrometeoizdat, (Russian) pp.172$177,2000$.

[3] State Review. Environment in Russia, 2000. Ministry of Natural Resources and Environment, Moscow, (Russian) pp. 325-409, 2001.

[4] Statistical data. Russian and regions. 2000. State Statistical Committee, Moscow, (Russian) pp.1-306, 2001.

[5] Review of Environmental Pollution on the territory of Russia, 2000. State Hydrometeorology Service of Russia, Moscow, Hydrometeoizdat, (Russian) pp.1-245, 2001. 
